Document downloaded from:

http://hdl.handle.net/10251/133754

This paper must be cited as:

Moliner, C.; Badia, J.; Bosio, B.; Arato, E.; Teruel-Juanes, R.; Kittikorn, T.; Stromberg, E.... (2018). Thermal kinetics for the energy valorisation of polylactide/sisal biocomposites.

Thermochimica Acta. 670:169-177. https://doi.org/10.1016/j.tca.2018.10.029

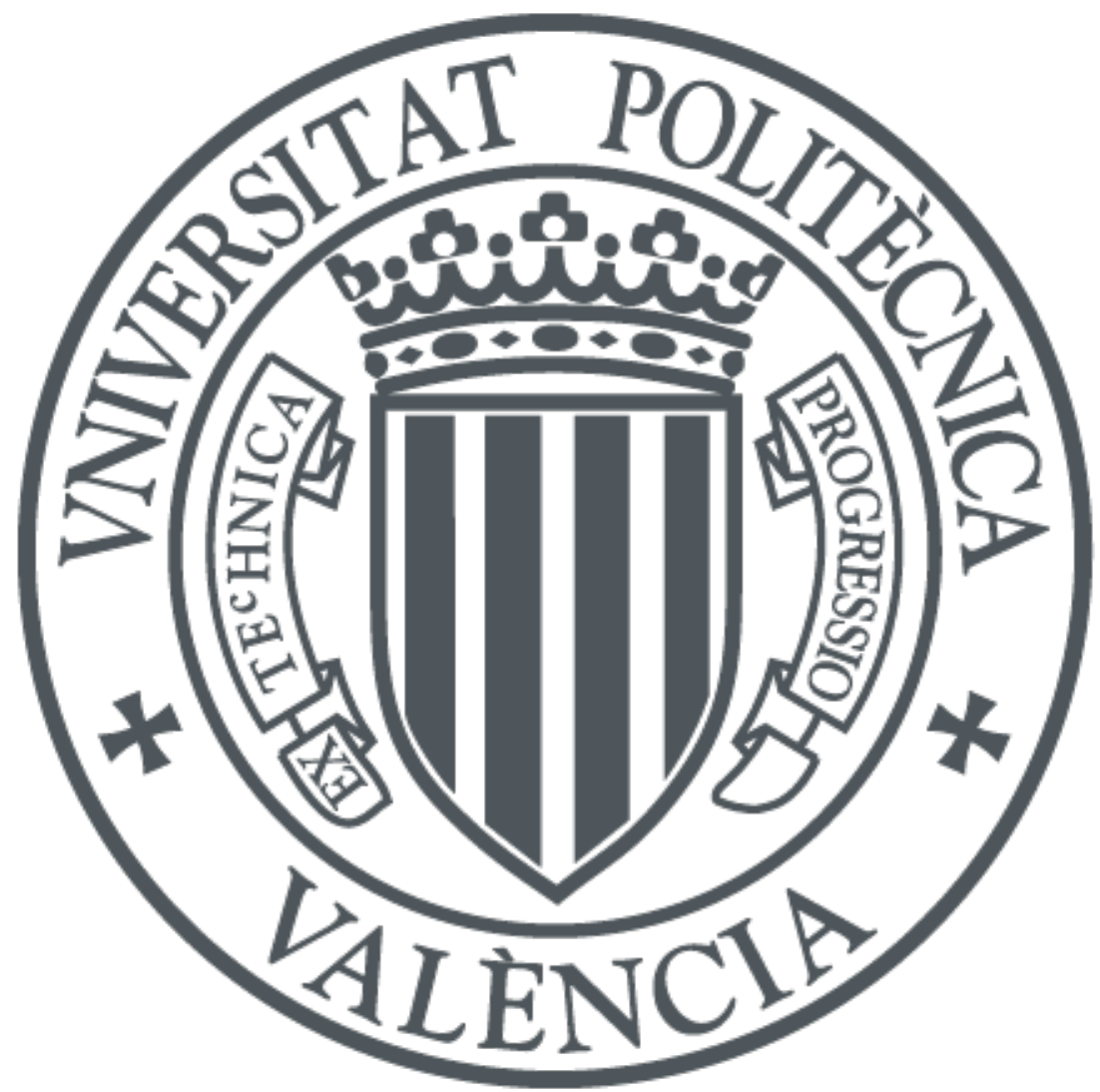

The final publication is available at

https://doi.org/10.1016/j.tca.2018.10.029

Copyright Elsevier

Additional Information 


\title{
THERMAL KINETICS FOR THE ENERGY VALORISATION OF POLYLACTIDE/SISAL BIOCOMPOSITES
}

\author{
C.Moliner ${ }^{1,2}$, J.D. Badia ${ }^{2,3}$, B. Bosio ${ }^{1}$, E. Arato1, R. Teruel-Juanes'2, T. Kittikorn ${ }^{4,5}$, E. \\ Strömberg ${ }^{4}$, M.Ek ${ }^{4}$, S.Karlsson ${ }^{4}$, A.Ribes-Greus ${ }^{2, *}$
}

This is an open-access version, according to http://www.sherpa.ac.uk/romeo/issn/0040-6031/es/

Full text available at https://www.sciencedirect.com/science/article/pii/S0040603118306178

\author{
DOI: https://doi.org/10.1016/j.tca.2018.10.029
}

\section{Please, cite it as:}

C. Moliner, J.D. Badia, B. Bosio, E. Arato, R. Teruel-Juanes, T. Kittikorn, E. Strömberg, M. Ek, S. Karlsson, A. Ribes-Greus, Thermal kinetics for the energy valorisation of polylactide/sisal biocomposites,

Thermochimica Acta, Volume 670, 2018,169-177

${ }^{1}$ Dipartimento di Ingegneria Civile, Chimica e Ambientale (DICCA),Università degli Studi di Genova, Via Opera Pia 15, 16145 Genova (Italy)

${ }^{2}$ Instituto de Tecnología de los Materiales (ITM), Universidad Politècnica de València (UPV) Camino de Vera S/N, 46022 Valencia, Spain.

${ }^{3}$ Departament d'Enginyeria Química. Escola Tècnica Superior d'Enginyeria. Universitat de València. Av. de la Universitat, s/n, 46100, Burjassot, Spain.

${ }^{4}$ School of Chemical Science and Engineering, Fibre and Polymer Technology, KTH - Royal Institute of Technology, Teknikrigen 56-58, SE-10044 Stockholm, Sweden.

${ }^{5}$ Department of Materials Science and Technology, Faculty of Science, Prince of Songkla University Songkhla, 90112, Thailand.

*Corresponding author: A. Ribes-Greus aribes@ter.upv.es 


\title{
THERMAL KINETICS FOR THE ENERGY VALORISATION OF POLYLACTIDE/SISAL BIOCOMPOSITES
}

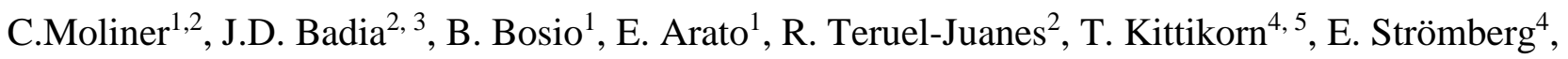 \\ M.Ek $^{4}$, S.Karlsson ${ }^{4}$, A.Ribes-Greus ${ }^{2, *}$ \\ ${ }^{1}$ Dipartimento di Ingegneria Civile, Chimica e Ambientale (DICCA),Università degli Studi di Genova, Via Opera Pia \\ 15, 16145 Genova (Italy) \\ ${ }^{2}$ Instituto de Tecnología de los Materiales (ITM), Universidad Politècnica de València (UPV) \\ Camino de Vera S/N, 46022 Valencia, Spain. \\ ${ }^{3}$ Departament d'Enginyeria Química. Escola Tècnica Superior d'Enginyeria. Universitat de València. Av. de la \\ Universitat, s/n, 46100, Burjassot, Spain. \\ ${ }^{4}$ School of Chemical Science and Engineering, Fibre and Polymer Technology, KTH - Royal Institute of Technology, \\ Teknikrigen 56-58, SE-10044 Stockholm, Sweden. \\ ${ }^{5}$ Department of Materials Science and Technology, Faculty of Science, Prince of Songkla University \\ Songkhla, 90112, Thailand. \\ *Corresponding author: A. Ribes-Greus aribes@ter.upv.es
}

\begin{abstract}
The thermal stability and decomposition kinetics of PLA/sisal biocomposites was discussed to evaluate the suitability of their use in energy recovery processes such as pyrolysis and combustion. The influence of the addition of sisal up to $30 \% \mathrm{wt}$, the presence of coupling agent, and the atmosphere of operation, i.e. inert or oxidative was discussed by means of multi-rate linear nonisothermal thermogravimetric experiments. All biocomposites showed a mean high heating value of $15 \mathrm{MJ} / \mathrm{kg}$ indicating their suitability for energy recovery processes. The thermal requirements of PLA/sisal decomposition were assessed in terms of onset decomposition temperature and apparent activation energy. A minimum of $240{ }^{\circ} \mathrm{C}$ and $174 \mathrm{~kJ} \cdot \mathrm{mol}^{-1}$ in inert environment and $225^{\circ} \mathrm{C}$ and 190 $\mathrm{kJ} \cdot \mathrm{mol}^{-1}$ in oxidative environment ensured the feasibility of the reactions regardless the composition of the PLA/sisal biocomposites. The atmosphere of work lead to a greater amount of residue in case of pyrolysis reactions that would need further treatment whereas an oxidative atmosphere resulted in nearly zero final waste stream. The similar kinetics obtained for all samples regardless the amount of sisal or use of coupling agent eases the operability of energy facilities aimed of turning these biowastes into new fuels.
\end{abstract}


C. Moliner, J.D. Badia, B. Bosio, E. Arato, R. Teruel-Juanes, T. Kittikorn, E. Strömberg, M. Ek, S. Karlsson, A. Ribes-Greus, Thermal kinetics for the energy valorisation of polylactide/sisal biocomposites, Thermochimica Acta, Volume 670, 2018,169-177

Keywords: energy valorisation; thermal decomposition, kinetics; biocomposites; polylactide (PLA); natural fibres;

\section{List of abbreviations and symbols}

$\alpha$ Degree of conversion

$\beta$ Heating rate of thermogravimetric analysis $\left({ }^{\circ} \mathrm{C} \cdot \mathrm{min}^{-1}\right)$

$\Delta \mathrm{m}_{\mathrm{i}}$ Mass loss of the decomposition process $\mathrm{i}(\%)$

A Pre-exponential factor

CA Coupling agent

DoE Design of Experiments

DTG first-derivative thermogravimetric curve

E Effect

Ea Apparent activation energy $\left(\mathrm{J} \cdot \mathrm{mol}^{-1}\right)$

$\mathrm{Ea}_{\text {iso }}$ Average apparent activation energy $\left(\mathrm{J} \cdot \mathrm{mol}^{-1}\right)$

F Factor

FWO Flynn-Wall-Ozawa

KAS Kissinger-Akahira-Sunose

L Level

MEP Main effects plot 
C. Moliner, J.D. Badia, B. Bosio, E. Arato, R. Teruel-Juanes, T. Kittikorn, E. Strömberg, M. Ek, S. Karlsson, A. Ribes-Greus, Thermal kinetics for the energy valorisation of polylactide/sisal biocomposites, Thermochimica Acta, Volume 670, 2018,169-177

MP Master plots

$\mathrm{MP}_{f, g}$ Differential (f) and integral (g) form of MP

$\mathrm{n}$ Reaction order in kinetic functions

PLA Polylactide

TG Thermogravimetric curve

TGA Thermogravimetric analysis

$\mathrm{T}_{0}$ Onset temperature $\left({ }^{\circ} \mathrm{C}\right)$

$\mathrm{T}_{\mathrm{e}}$ Endset temperature $\left({ }^{\circ} \mathrm{C}\right)$

$\mathrm{T}_{\mathrm{pi}}$ Peak temperature of decomposition process $\mathrm{i}\left({ }^{\circ} \mathrm{C}\right)$

VYZ Vyazovkin 


\section{Introduction}

The eco-design of biopolymers is usually focused on raw materials from renewable resources, optimisation of performance and reduction of wastes by biological valorisation (Badia et al., 2017a, 2017b)[1]. The replacement of polymer commodities such as polyethylene (PE), polypropylene (PP) or polyethylene-terephthalate (PET), by biopolymers is in increasing trend (Niaounakis, M. (2015) in different sectors such as automotive (de Moura et al. 2017), packaging (Coles \& Meredith, 2014) or building (Pacheco-Torgal, 2016), among others, whichwill result in a considerable new biopolymeric waste stream, and the facilities for material or biological valorisation such as composters might not be enough to cover the demand. In this sense, the energy valorisation of bio-based materials once their service life has been completed still remains as an interesting niche for research and development (Al-Salem et al., 2009).

Biocomposites based on polylactide matrix and natural fibres like sisal as mechanical reinforcement are one of the current developed green materials, which come from agricultural and forestry biomass (Oksman et al. 2003). The addition of coupling agents in the formulation of the biocomposites is commonly considered to pursue better interface adhesion and improve the performance of the PLA/sisal biocomposites (Gil-Castell et al. 2016a, 2016b, Badia et al., 2017c). However, these added components may alter the thermal requirements for energy valorisation and should be taken into account when designing thermal valorisation facilities. The application of thermo-chemical operations must be carefully evaluated and the knowledge of the thermal behavior of materials is of primary importance in the selection of appropriate operational parameters for the valoriser. 
Thermogravimetric Analysis (TGA) is a reliable technique to assess the thermal stability and decomposition kinetics of biopolymers by means of multi-rate isoconversional methods under the desired conditions of work. The assessment of the temperature of start and end of decomposition (i.e. onset and endset temperature), the evaluation of the apparent activation energy and the description of the decomposition process by means of a kinetic function are relevant parameters for the design and scale-up of energy valorisers (Moliner at al. 2016a, 2016b). Recently, several works address the study of the decomposition profile and kinetics expressions for biopolymers, biomass and biocomposites such as corn stalk (Cai et al. 2017), prosopis juliflora (Chandrasekaran et al. 2017), camel grass (Mehmood et al. 2017), chitin and chitosan (Moussou et al. 2016), PBAT/coffee (Moustafa et al. 2017), PBS/natural fibres (Dorez et al. 2013), polylactide (Badia et al. 2012b, GilCastell et al. 2018) or PHBV/sisal (Moliner et al. 2017a) which indicates the increasing trend to consider them as suitable materials for energy valorisation processes.

The purpose of this work is to assess the thermal stability and decomposition kinetics of biocomposites based on polylactide and sisal fibre through inert and oxidative decomposition by multi-rate thermogravimetric analysis with the aim to evaluate their feasibility for energy valorisation processes, i.e. pyrolysis and combustion, respectively. This study may represent the limiting operational requirements for thermo-chemical processes that use air under industrial conditions (Fang et al. 2006). The influence of the amount of sisal and the presence of coupling agent in the biocomposites was also evaluated. The suitability of their use in pyrolysis or combustion process was discussed in terms of thermal kinetics and minimum thermal requirements for their energy valorisation. 


\section{Experimental procedures}

\subsection{Materials and sample preparation}

Polylactide (PLA) 3251D was purchased from Natureworks (Minnetonka, USA) as pellets with a glass transition in $65-70{ }^{\circ} \mathrm{C}$ range. Sisal fibres, a farming crop, were supplied by the Thai Royal Project (Kittikorn, 2013). Maleic anhydride (MAH) M188-99\% (Sigma-Aldrich, Sweden AB) and dicumyl peroxide (DCP) 98\% (Sigma-Aldrich, Sweden AB) were used as coupling agent and free radical initiator, respectively.

Virgin PLA (PLA) and sisal fibre were initially dried in an oven at $80{ }^{\circ} \mathrm{C}$ for 12 hours and then kept in zip bags. The fibre contents in the biocomposite were $10 \%, 20 \%$ and $30 \%$ by weight with and without coupling agent. In case of not using coupling agent, composites were prepared in an internal mixer (Brabender, Germany) during 5 minutes at $180{ }^{\circ} \mathrm{C}$ and at the speed of $50 \mathrm{rpm}$. The resulting biocomposites were labelled as PLA10, PLA20 and PLA30 according to previous optimisation results (Kittikorn, 2013). Biocomposites containing the coupling agent were prepared by incorporating MAH $2.5 \%$ and DCP $0.3 \%$ (w/w) in molten polymer and mixing during 5 minutes at $180^{\circ} \mathrm{C}$ and at the speed of $50 \mathrm{rpm}$. These samples were labelled as PLA10CA, PLA20CA and PLA30CA. PLA/sisal biocomposites were then ground and the granules dried at $80{ }^{\circ} \mathrm{C}$ in the oven during at least $12 \mathrm{~h}$.

A compression moulding equipment (Fontijne Presses, Netherlands) was used for the obtainment of the final samples. The biocomposites preparation procedure was: preheating the press at $200{ }^{\circ} \mathrm{C}$ for 2 min, and application of a compression force of $150 \mathrm{kN}$ for maximum $2 \mathrm{~min}$ to minimise the potential degradation effects that could be produced. An automatic cooling procedure of the hot press was performed. All the compression moulding operations were performed under vacuum conditions. The thickness of the sheet samples was $0.5 \pm 0.1 \mathrm{~mm}$. 
C. Moliner, J.D. Badia, B. Bosio, E. Arato, R. Teruel-Juanes, T. Kittikorn, E. Strömberg, M. Ek, S. Karlsson, A. Ribes-Greus, Thermal kinetics for the energy valorisation of polylactide/sisal biocomposites, Thermochimica Acta, Volume 670, 2018,169-177

Finally, all biocomposites were dried at $50{ }^{\circ} \mathrm{C}$ in a vacuum oven (Heraeus Vacutherm 6025, Germany), then kept in zip bags and placed in a desiccator for further analyses at normalized lab conditions according to ISO 291 (ISO 291).

Moreover, all samples were characterised by their proximate analysis from Standard ASTM D-5373 (ASTM, 2002). Calorific values were also determined through the application of suitable correlations.

\subsection{Thermogravimetric analyses}

Multi-rate linear non-isothermal thermogravimetric analyses (TGA) were carried out in a Mettler Toledo TGA/SDTA 851 (Columbus, OH) thermogravimetric analyser. Samples weighing around 7 mg were heated in an alumina holder with capacity for $70 \mu \mathrm{L}$. The size of samples was around $2 \times 2$ $\mathrm{mm}$ to minimise mass and heat transfer phenomena. Experiments were performed from $25{ }^{\circ} \mathrm{C}$ to $800{ }^{\circ} \mathrm{C}$ at different heating rates $\left(\beta=2,5,10,20^{\circ} \mathrm{C} \cdot \mathrm{min}^{-1}\right)$ under constant flow of $50 \mathrm{~mL} \cdot \mathrm{min}^{-1}$ of gas of analysis. All analyses were set under inert (Ar) and oxidative $\left(\mathrm{O}_{2}\right)$ atmospheres to characterise the inert and oxidative processes, respectively. A previous blank curve was performed before each set of experiments to reduce probable buoyancy effects (Prime et al. 2008). The experiments were repeated three times and the average of the characteristic TGA temperatures, along with the masslosses of each decomposition stage, were considered as representative values.

\subsection{Statistical Assessment}

A statistical procedure of data analysis was performed in order to assess the individual influence of each studied variable (Box et al. 2005). The influence of each input variable (Factor) at the different tested values (Levels) was analysed by means of Main Effect Plots (MEP), as shown elsewhere (Badia et al. 2011, 2017b). 
The Factors/Levels under consideration were (i) fibre amount (wt\%) / 0, 10, 20, 30; (ii) use of coupling agent / NO, YES; and (iii) atmosphere of analysis / Ar, $\mathrm{O}_{2}$. The Effects chosen for the analysis were the experimental outputs of characteristic temperatures and mass losses.

\section{Results and discussion}

Firstly, the biocomposites composition and their calorific values were evaluated to ensure the suitability of these materials for energy recovery (Section 3.1).

Once proved valid, the thermal performance of PLA and PLA/sisal biocomposites was initially addressed to evaluate the thermal requirements and stages of inert and oxidative decomposition (Section 3.2). Afterwards, the apparent activation energy variation along the mass-to-energy conversion process was evaluated by means of the isoconversional methods. Finally, a kinetic triplet and appropriate operational inputs for energetic valorisation of PLA and PLA/sisal biocomposites were proposed (Section 3.3).

As a result of the applied methodology, the temperature ranges to define the most adequate operating parameters for the valoriser and the kinetic expression describing the rate of decomposition of the biocomposites as a function of the applied temperature were obtained and discussed for all materials.

This research represents the limiting operational values for the energy valorisation of PLA/sisal as a feedstock. Once these limits are established, the different possibilities that fall within the thermochemical range can be studied by adapting their adequate operational conditions. For example, the use of air will lead to lower reaction temperatures compared to those obtained in the present work, as reported in literature (Fang et al. 2006). 


\subsection{Biocomposites composition and calorific values}

The compositions of all samples are gathered in Table 1. Calorific values were determined from the proximate analysis through the correlation by Parikh et al. (2005):

$\mathrm{HHV}(\mathrm{MJ} / \mathrm{kg}$, dry basis $)=0.3536 \mathrm{FC}+0.1559 \mathrm{VM}-0.0078 \mathrm{Ash}$

with FC: \%wt fixed carbon, VM: \%wt volatile matter, Ash: \%wt ash content

Table 1. Proximate analysis and high calorific value for PLA/Sisal biocomposites

\begin{tabular}{l|lllllll} 
Sample & PLA & PLA10 & PLA20 & PLA30 & PLA10CA & PLA20CA & PLA30CA \\
\hline Proximate analysis (wt\% db) & & & & & & \\
Ash & 0,6 & 3,0 & 4,7 & 6,0 & 1,9 & 4,4 & 6,0 \\
Volatile Matter & 98,2 & 95,6 & 93,6 & 91,7 & 95,6 & 93,5 & 91,2 \\
Fixed Carbon (diff) & 1,2 & 1,4 & 1,7 & 2,3 & 2,5 & 2,1 & 2,8 \\
\hline $\begin{array}{l}\text { High Calorific Value } \\
\text { (MJ/kg) }\end{array}$ & 15,73 & 15,37 & 15,16 & 15,06 & 15,77 & 15,28 & 15,16 \\
& & & & & & &
\end{tabular}

Remarkably, a high mean calorific value $(15 \mathrm{MJ} / \mathrm{kg})$ was obtained for all samples which showed their suitability to be used for energy recovery purposes in line with other biomaterials already proposed as energy vectors like rice straw: $13 \mathrm{MJ} / \mathrm{kg}$ (Moliner et al, 2016a) or prosopis juliflora: 16 $\mathrm{MJ} / \mathrm{kg}$ (Seethalakshmi et al. 2013).

\subsection{Assessment stability of the biocomposites: inert and oxidative conditions}

The thermogravimetric curves (TG) were obtained for each biocomposite at all $\beta$ under inert and oxidative atmospheres. The descriptive profiles of inert and oxidative decomposition are shown in Fig 1. 
C. Moliner, J.D. Badia, B. Bosio, E. Arato, R. Teruel-Juanes, T. Kittikorn, E. Strömberg, M. Ek, S. Karlsson, A. Ribes-Greus, Thermal kinetics for the energy valorisation of polylactide/sisal biocomposites, Thermochimica Acta, Volume 670, 2018,169-177
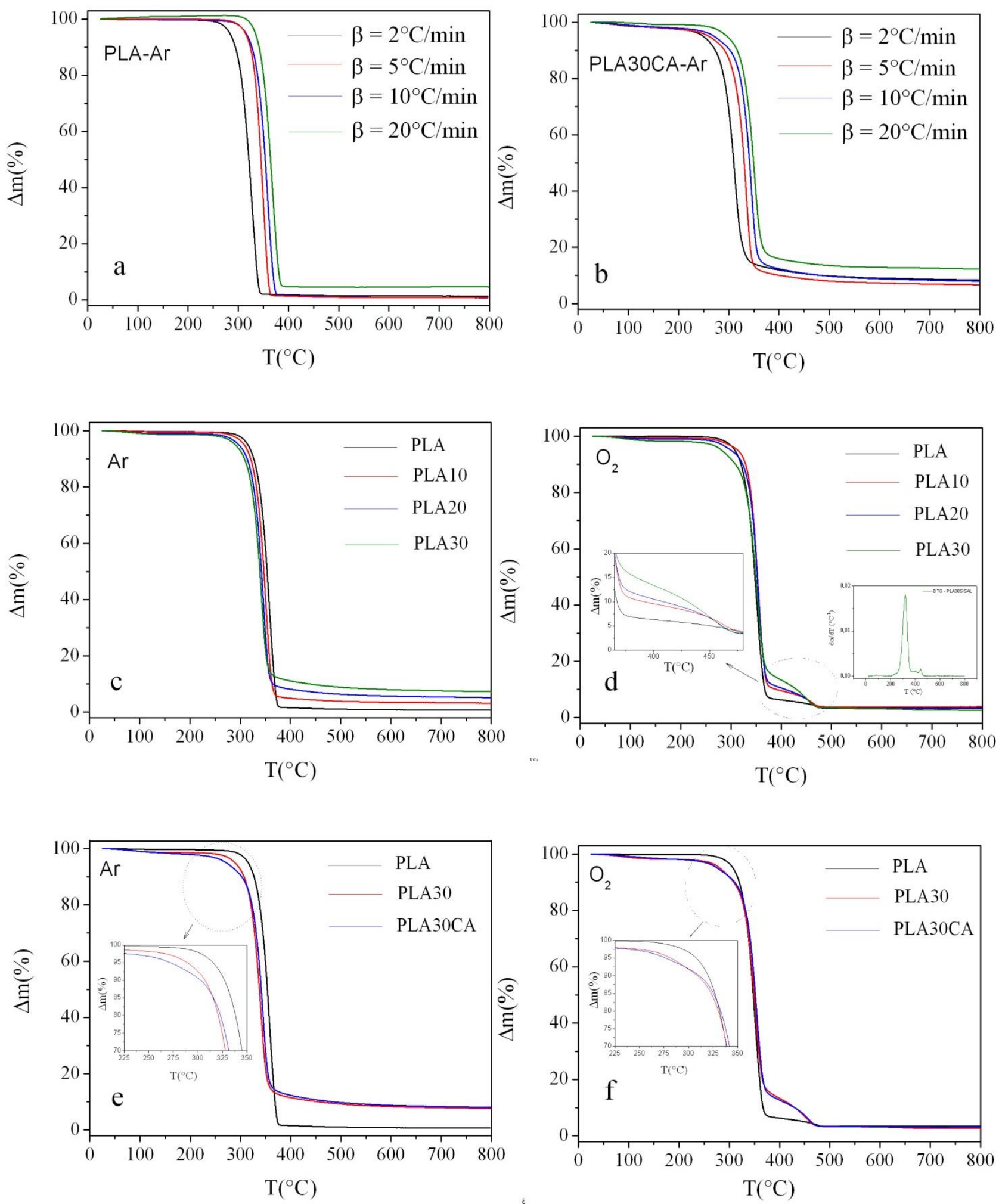

Figure 1. Thermogravimetric (TG) curves for PLA (a) and PLA30CA (b) for all $\beta$ at inert atmosphere; TG curve at $\beta=10^{\circ} \mathrm{C} \cdot \mathrm{min}^{-1}$ for PLA and the corresponding composites, under both inert (c) and oxidative (d) atmospheres; Influence of the addition of CA on the decomposition of PLA biocomposites under both inert (e) and oxidative (f) atmospheres. 
The experimental effect of the heating rate used in TGA is shown in Fig 1a for neat PLA and Fig $1 \mathbf{b}$ for PLA30CA as model cases. As expected, higher $\beta$ shifted the thermograms to higher temperatures. The influence of the addition of sisal fibre into the formulation of PLA/sisal biocomposites can also be studied from Fig 1a and Fig 1b for PLA and PLA30CA respectively. The samples were taken as model cases due to their performance as extreme cases with the TG curves of the rest of PLA/sisal biocomposites laying in between them.

The onset of decomposition started at lower temperatures and ended at higher temperatures the larger the load of sisal was, regardless the atmosphere of work. This fact can be checked in Table 2 where the temperatures of start (onset- $\mathrm{T}_{0}$ ) and end of decomposition (endset- $\mathrm{T}_{\mathrm{e}}$ ) for PLA and PLA/sisal biocomposites are gathered. The same decreasing trend was followed by the temperatures at maximum mass loss rate. They were obtained from the minimum of the first-derivate thermogravimetric (DTG) curves, i.e. peak temperatures $\left(T_{p}\right)$ and are gathered in Table 3 for all processes.

The repercussion of the atmosphere of work is pictured in Fig 1c and Fig 1d, where the TG curves at $\beta=10^{\circ} \mathrm{C} \cdot \mathrm{min}^{-1}$ for PLA and the corresponding PLA/sisal biocomposites without coupling agent are shown. Additionally, with the aim of describing the individual steps, a deconvolution procedure was applied to all samples following the methodology explained elsewhere (Badia et al. 2010). The mass-losses associated to each decomposition stage studied at $\beta=2{ }^{\circ} \mathrm{C} \cdot \mathrm{min}^{-1}$, for which the phenomena of thermal inertia are minimised, are given in Table 3. 
C. Moliner, J.D. Badia, B. Bosio, E. Arato, R. Teruel-Juanes, T. Kittikorn, E. Strömberg, M. Ek, S. Karlsson, A. Ribes-Greus, Thermal kinetics for the energy valorisation of polylactide/sisal biocomposites, Thermochimica Acta, Volume 670, 2018,169-177

Table 2. Characteristic temperatures $\left(T_{0}, T_{\mathrm{e}}\right)$ and $\Delta T$ for PLA/Sisal biocomposites $\left(\mathrm{Ar}-\mathrm{O}_{2}\right)$ at 2 ${ }^{\circ} \mathrm{C} / \mathrm{min}$ and associated error values (e)

\begin{tabular}{lccccc|ccccc}
\multicolumn{9}{c}{$\mathbf{A r}$} & \multicolumn{5}{c}{$\mathbf{O}_{\mathbf{2}}$} \\
\hline Material & $\mathbf{T}_{\mathbf{0}}\left({ }^{\mathbf{0}} \mathbf{C}\right)$ & $\mathbf{e}(\boldsymbol{\%})$ & $\mathbf{T}_{\mathbf{e}}\left({ }^{\mathbf{0}} \mathbf{C}\right)$ & $\mathbf{e}(\boldsymbol{\%})$ & $\Delta \mathbf{T}\left({ }^{\mathbf{}} \mathbf{C}\right)$ & $\mathbf{T}_{\mathbf{0}}\left({ }^{\mathbf{0}} \mathbf{C}\right)$ & $\mathbf{e}(\boldsymbol{\%})$ & $\mathbf{T}_{\mathbf{e}}\left({ }^{\mathbf{}} \mathbf{C}\right)$ & $\mathbf{e}(\boldsymbol{\%})$ & $\Delta \mathbf{T}\left({ }^{\mathbf{0}} \mathbf{C}\right)$ \\
\hline PLA & 239 & $\pm 1,3$ & 351 & \pm 3 & 112 & 209 & $\pm 0,4$ & 455 & $\pm 1,6$ & 246 \\
PLA10 & 232 & $\pm 0,7$ & 359 & \pm 2 & 127 & 216 & $\pm 0,3$ & 458 & $\pm 0,8$ & 242 \\
PLA20 & 228 & $\pm 1,4$ & 362 & $\pm 1,7$ & 134 & 221 & $\pm 0,4$ & 478 & $\pm 1,7$ & 257 \\
PLA30 & 228 & $\pm 0,8$ & 356 & $\pm 1,9$ & 128 & 221 & $\pm 1,0$ & 475 & $\pm 0,8$ & 254 \\
PLA10CA & 220 & \pm 2 & 355 & \pm 2 & 135 & 225 & $\pm 0,5$ & 467 & $\pm 0,4$ & 242 \\
PLA20CA & 222 & $\pm 1,1$ & 355 & $\pm 1,5$ & 133 & 215 & $\pm 0,3$ & 471 & $\pm 0,9$ & 256 \\
PLA30CA & 215 & $\pm 0,8$ & 363 & $\pm 1,8$ & 148 & 210 & $\pm 0,9$ & 479 & $\pm 1,3$ & 269 \\
\hline
\end{tabular}

Table 3. Characteristic temperatures $\left(\mathrm{T}_{\mathrm{p} 1}, \mathrm{~T}_{\mathrm{p} 2}, \mathrm{~T}_{\mathrm{p} 3}\right)$ for PLA/Sisal biocomposites $\left(\mathrm{Ar}-\mathrm{O}_{2}\right)(2,5$, $10,20^{\circ} \mathrm{C} / \mathrm{min}$ ) and associated error values (e)

\begin{tabular}{|c|c|c|c|c|c|c|c|c|c|}
\hline & \multicolumn{3}{|c|}{$\mathbf{A r}$} & \multicolumn{6}{|c|}{$\mathbf{O}_{2}$} \\
\hline & Material & $\mathbf{T}_{\mathrm{p} 1}\left({ }^{\circ} \mathrm{C}\right)$ & e $(\%)$ & $\mathbf{T}_{\mathrm{p} 1}\left({ }^{\circ} \mathrm{C}\right)$ & e $(\%)$ & $\mathbf{T}_{\mathrm{p} 2}\left({ }^{\circ} \mathrm{C}\right)$ & e (\%) & $\mathbf{T}_{\mathrm{p} 3}\left({ }^{\circ} \mathrm{C}\right)$ & e $(\%)$ \\
\hline \multirow{8}{*}{$2^{\circ} \mathrm{C} / \mathrm{min}$} & PLA & 327 & $\pm 1,8$ & 329 & $\pm 0,4$ & - & - & 416 & $\pm 0,7$ \\
\hline & PLA10 & 324 & \pm 2 & 312 & $\pm 1,2$ & 331 & $\pm 0,9$ & 405 & $\pm 1,5$ \\
\hline & PLA20 & 316 & $\pm 0,7$ & 309 & $\pm 0,4$ & 330 & $\pm 0,7$ & 402 & $\pm 0,3$ \\
\hline & PLA30 & 303 & $\pm 0,5$ & 301 & $\pm 1,1$ & 325 & $\pm 0,7$ & 403 & $\pm 0,8$ \\
\hline & PLA10CA & 322 & \pm 2 & 316 & $\pm 1,9$ & 332 & $\pm 1,3$ & 409 & $\pm 1,1$ \\
\hline & PLA20CA & 319 & $\pm 1,2$ & 312 & \pm 2 & 330 & $\pm 1,2$ & 403 & $\pm 1,3$ \\
\hline & PLA30CA & 316 & $\pm 0,8$ & 302 & $\pm 0,5$ & 327 & $\pm 0,9$ & 407 & $\pm 1,1$ \\
\hline & Material & $\mathrm{T}_{\mathrm{p} 1}\left({ }^{\circ} \mathrm{C}\right)$ & e (\%) & $\mathrm{T}_{\mathrm{p} 1}\left({ }^{\circ} \mathrm{C}\right)$ & e $(\%)$ & $\mathrm{T}_{\mathrm{p} 2}\left({ }^{\circ} \mathrm{C}\right)$ & e (\%) & $\mathrm{T}_{\mathrm{p} 3}\left({ }^{\circ} \mathrm{C}\right)$ & e $(\%)$ \\
\hline \multirow{8}{*}{$5^{\circ} \mathrm{C} / \mathrm{min}$} & PLA & 348 & $\pm 0,5$ & 343 & $\pm 0,3$ & - & - & 447 & $\pm 0,5$ \\
\hline & PLA10 & 336 & $\pm 0,7$ & 331 & $\pm 0,5$ & 345 & $\pm 0,6$ & 428 & $\pm 0,4$ \\
\hline & PLA20 & 324 & $\pm 0,5$ & 331 & $\pm 0,2$ & 345 & $\pm 0,3$ & 426 & $\pm 0,2$ \\
\hline & PLA30 & 318 & $\pm 0,9$ & 325 & $\pm 0,1$ & 339 & $\pm 0,7$ & 421 & $\pm 0,2$ \\
\hline & PLA10CA & 334 & $\pm 0,2$ & 324 & $\pm 0,1$ & 343 & $\pm 0,2$ & 427 & $\pm 0,3$ \\
\hline & PLA20CA & 348 & $\pm 0,3$ & 328 & $\pm 0,3$ & 344 & $\pm 0,1$ & 425 & $\pm 0,2$ \\
\hline & PLA30CA & 333 & $\pm 0,1$ & 325 & $\pm 0,1$ & 342 & $\pm 0,1$ & 426 & $\pm 0,3$ \\
\hline & Material & $\mathrm{T}_{\mathrm{p} 1}\left({ }^{\circ} \mathrm{C}\right)$ & e (\%) & $\mathrm{T}_{\mathrm{p} 1}\left({ }^{\circ} \mathrm{C}\right)$ & e (\%) & $\mathrm{T}_{\mathrm{p} 2}\left({ }^{\circ} \mathrm{C}\right)$ & e (\%) & $\mathrm{T}_{\mathrm{p} 3}\left({ }^{\circ} \mathrm{C}\right)$ & e $(\%)$ \\
\hline \multirow{8}{*}{$10^{\circ} \mathrm{C} / \mathrm{min}$} & PLA & 357 & $\pm 0,7$ & 350 & $\pm 0,6$ & - & - & 478 & $\pm 0,8$ \\
\hline & PLA10 & 350 & $\pm 0,5$ & 340 & $\pm 0,4$ & 348 & $\pm 0,4$ & 429 & \pm 4 \\
\hline & PLA20 & 345 & $\pm 0,4$ & 337 & $\pm 0,6$ & 354 & $\pm 0,2$ & 442 & $\pm 0,8$ \\
\hline & PLA30 & 342 & $\pm 0,4$ & 329 & $\pm 0,4$ & 351 & $\pm 0,1$ & 437 & $\pm 0,7$ \\
\hline & PLA10CA & 348 & $\pm 1,1$ & 338 & $\pm 0,4$ & 355 & $\pm 0,8$ & 442 & $\pm 0,5$ \\
\hline & PLA20CA & 348 & $\pm 0,7$ & 337 & $\pm 0,3$ & 355 & $\pm 0,3$ & 441 & $\pm 0,5$ \\
\hline & PLA30CA & 345 & $\pm 0,6$ & 337 & $\pm 0,4$ & 354 & $\pm 0,7$ & 443 & $\pm 0,6$ \\
\hline & Material & $\mathrm{T}_{\mathrm{p} 1}\left({ }^{\circ} \mathrm{C}\right)$ & e (\%) & $\mathrm{T}_{\mathrm{p} 1}\left({ }^{\circ} \mathrm{C}\right)$ & e $(\%)$ & $\mathrm{T}_{\mathrm{p} 2}\left({ }^{\circ} \mathrm{C}\right)$ & e (\%) & $\mathrm{T}_{\mathrm{p} 3}\left({ }^{\circ} \mathrm{C}\right)$ & e $(\%)$ \\
\hline \multirow{5}{*}{$20^{\circ} \mathrm{C} / \mathrm{min}$} & PLA & 370 & $\pm 0,2$ & 365 & $\pm 0,2$ & - & - & 482 & $\pm 0,4$ \\
\hline & PLA10 & 355 & $\pm 0,1$ & 350 & $\pm 0,3$ & 368 & $\pm 0,2$ & 457 & $\pm 0,4$ \\
\hline & PLA20 & 347 & $\pm 0,2$ & 353 & $\pm 0,1$ & 362 & $\pm 0,1$ & 461 & $\pm 0,6$ \\
\hline & PLA30 & 351 & $\pm 0,3$ & 338 & $\pm 0,1$ & 362 & $\pm 0,2$ & 459 & $\pm 0,7$ \\
\hline & PLA10CA & 354 & $\pm 0,2$ & 349 & $\pm 0,2$ & 367 & $\pm 0,1$ & 461 & $\pm 0,9$ \\
\hline
\end{tabular}


C. Moliner, J.D. Badia, B. Bosio, E. Arato, R. Teruel-Juanes, T. Kittikorn, E. Strömberg, M. Ek, S. Karlsson, A. Ribes-Greus, Thermal kinetics for the energy valorisation of polylactide/sisal biocomposites, Thermochimica Acta, Volume 670, 2018,169-177

\begin{tabular}{|lll|llllll} 
PLA20CA & 354 & $\pm 0,5$ & 345 & $\pm 0,1$ & 364 & $\pm 0,3$ & 452 & $\pm 0,5$ \\
PLA30CA & 351 & $\pm 0,1$ & 341 & $\pm 0,2$ & 363 & $\pm 0,1$ & 461 & $\pm 0,4$
\end{tabular}

A single-step mass-loss process was observed under inert conditions (Fig 1c) indicated that the polymer matrix and the fibre decomposed at the same time. For this reason, the mass loss for pyrolysis in Table 3 is presented as the sum of both contributions $\left(\Delta \mathrm{m}_{1}+\Delta \mathrm{m}_{2}\right)$. The addition of natural fibres resulted in an increase on the final residue indicating that fibres were less prone to decompose in a non-reactive ambient.

A three-step mass-loss process was observed under an oxidative atmosphere, which almost consumed the whole mass of the PLA/sisal biocomposites, as can be checked at the inset of Fig 1d. The first step of the decomposition occurred at $\sim 315^{\circ} \mathrm{C}$ for all PLA/sisal biocomposites and neat PLA. A slight decrease of the mass loss associated to this process $\left(\Delta \mathrm{m}_{1}\right)$ was observed with the increase of the percentage of natural fibres in the biocomposites. Therefore, this mass-loss step was ascribed to the decomposition of the polymeric matrix, in agreement with literature (Kopinke et al. 1996). The second step occurred at around $330{ }^{\circ} \mathrm{C}$, eliminating an increasing quantity of mass $\left(\Delta \mathrm{m}_{2}\right)$ with the percentage of fibre in the matrix. Thus, this second step was related to the decomposition of sisal, in agreement with literature (Josep at al. 2003). Finally, a third step was observed assigned to the further breakage of the decomposition products from the previous step (Monteiro et al. 2012).

The onset temperature $T_{0}$ of samples with fibres decreased under inert conditions respect to the polymeric matrix, whereas the contrary trend was observed for oxidative environment (Table 2). This behaviour indicates that the addition of sisal to the PLA matrix moderately improved the thermal stability of the PLA/sisal biocomposites in oxidative reactions. 
This fact may be attributed to the enhancement on the reinforcing efficiency of the natural fibre based on the content of cellulose which is relatively resistant to oxidising agents (John et al. 2008). Lastly, the temperature of maximum mass loss rate was lower under oxidative than inert conditions, as a result of an increased reactivity in the system (Table 3).

The influence of the presence of coupling agent in the PLA/sisal biocomposites is shown at the TG profiles in Fig 1e and Fig 1f for the experiments under inert and oxidative atmospheres. It generally resulted in a decrease in the onset temperature of decomposition under inert conditions whereas no significant effect was observed when oxidative conditions were applied (Table 2). It was not relevant as well in terms of temperatures of maximum rate of decomposition (Table 3).

Concerning mass-losses, oxidative conditions provided lower residual percentages with a maximum value of $\sim 3 \%$ suggesting that the biopolymers were highly affected by oxidative reactions (Table 4). The higher amount of residue after pyrolysis respect with combustion should be carefully evaluated as it could represent a new waste stream requiring further treatments if no applications were found whereas the application of combustion would lead to a zero-waste scenario.

Table 4. Averaged associated mas loss $\left(\Delta \mathrm{m}_{1}, \Delta \mathrm{m}_{2}, \Delta \mathrm{m}_{3}\right)$ and remaining residue for PLA/Sisal biocomposites $\left(\mathrm{Ar}-\mathrm{O}_{2}\right)$ at $\beta=2{ }^{\circ} \mathrm{C} / \mathrm{min}$ and associated error values (e)

\begin{tabular}{|c|c|c|c|c|c|c|c|c|c|c|c|c|}
\hline & & & Ar & & & & & & $\mathrm{O}_{2}$ & & & \\
\hline Material & $\begin{array}{c}\Delta \mathbf{m}_{1}+\Delta \mathbf{m}_{2} \\
(\%)\end{array}$ & e (\%) & $\Delta \mathrm{m}_{3}(\%)$ & e (\%) & $\operatorname{Res}(\%)$ & $\Delta \mathrm{m}_{1}(\%)$ & e (\%) & $\Delta \mathrm{m}_{2}(\%)$ & e (\%) & $\Delta \mathrm{m}_{3}(\%)$ & e (\%) & $\operatorname{Res}(\%)$ \\
\hline PLA & 98,2 & \pm 2 & - & - & 1,8 & 90,2 & $\pm 2,4$ & - & - & 8,6 & \pm 2 & 1,2 \\
\hline PLA10 & 95,6 & \pm 3 & - & - & 4 & 75,2 & $\pm 3,4$ & 14,1 & \pm 2 & 9,3 & $\pm 1,4$ & 1,4 \\
\hline PLA20 & 93,6 & \pm 3 & - & - & 6 & 74,5 & $\pm 3,3$ & 15,2 & \pm 1 & 8,6 & $\pm 1,3$ & 1,7 \\
\hline PLA30 & 91,7 & \pm 2 & - & - & 8 & 71,8 & $\pm 3,6$ & 15,5 & \pm 2 & 10,4 & \pm 3 & 2,3 \\
\hline PLA10CA & 95,6 & \pm 3 & - & - & 4 & 67,8 & $\pm 4,2$ & 17,5 & \pm 3 & 12,2 & \pm 2 & 2,5 \\
\hline PLA20CA & 93,5 & \pm 2 & - & - & 6 & 68,6 & $\pm 4,3$ & 17,2 & \pm 3 & 12,1 & $\pm 1,3$ & 2,1 \\
\hline PLA30CA & 91,2 & \pm 3 & - & - & 9 & 68,1 & $\pm 3,4$ & 17,4 & \pm 3 & 11,7 & \pm 2 & 2,8 \\
\hline
\end{tabular}


In summary, a minimum temperature of $240{ }^{\circ} \mathrm{C}$ would be necessary to carry out the reaction of pyrolysis of the PLA and its biocomposites with sisal. For the case of oxidative reactions, $225{ }^{\circ} \mathrm{C}$ would be required in order to perform the complete oxidation of the biocomposites.

A statistical evaluation of the thermal properties of all samples has been performed in order to offer an overview of the effect of the addition of fibres, as well as the effect of the addition of CA and atmosphere of work on the main thermal parameters.

The Main Effect Plots (MEP) for the response variables $\mathrm{T}_{0}$ (a) and $\Delta \mathrm{m}_{1+} \Delta \mathrm{m}_{2}$ and $\Delta \mathrm{m}_{3}$ (b) are shown in Fig 2a and Fig 2b, respectively. The solid line represents the mean values in each case and the data relative position showed which factors influenced the response the most (Badia et al. 2011a, 2011b).

- The percentage of fibre and atmosphere of thermal operation was relevant for the onset temperature and the mass-losses. The coupling agent was relevant only for the onset temperature, but not for the mass-loss.

- Focusing on the onset temperature, the most relevant factor was the atmosphere, followed by the addition of fibre and use of coupling agent in a similar magnitudes, but contrary trends. While the addition of sisal diminished the trigger of thermal decomposition of the PLA/sisal biocomposites under inert conditions, the addition of coupling agent retarded it to higher temperatures, close to that of neat PLA.

- Concerning the mass-loss, the addition of fibre influenced in a contrary fashion the decrease of the $\Delta \mathrm{m}_{1}+\Delta \mathrm{m}_{2}$ related to the polylactide matrix and the increase of $\Delta \mathrm{m}_{3}$ related to the decomposition of the final highly carbonous species, which is clearly affected by the atmosphere of analysis, as seen in Table 3. 
C. Moliner, J.D. Badia, B. Bosio, E. Arato, R. Teruel-Juanes, T. Kittikorn, E. Strömberg, M. Ek, S. Karlsson, A. Ribes-Greus, Thermal kinetics for the energy valorisation of polylactide/sisal biocomposites, Thermochimica Acta, Volume 670, 2018,169-177
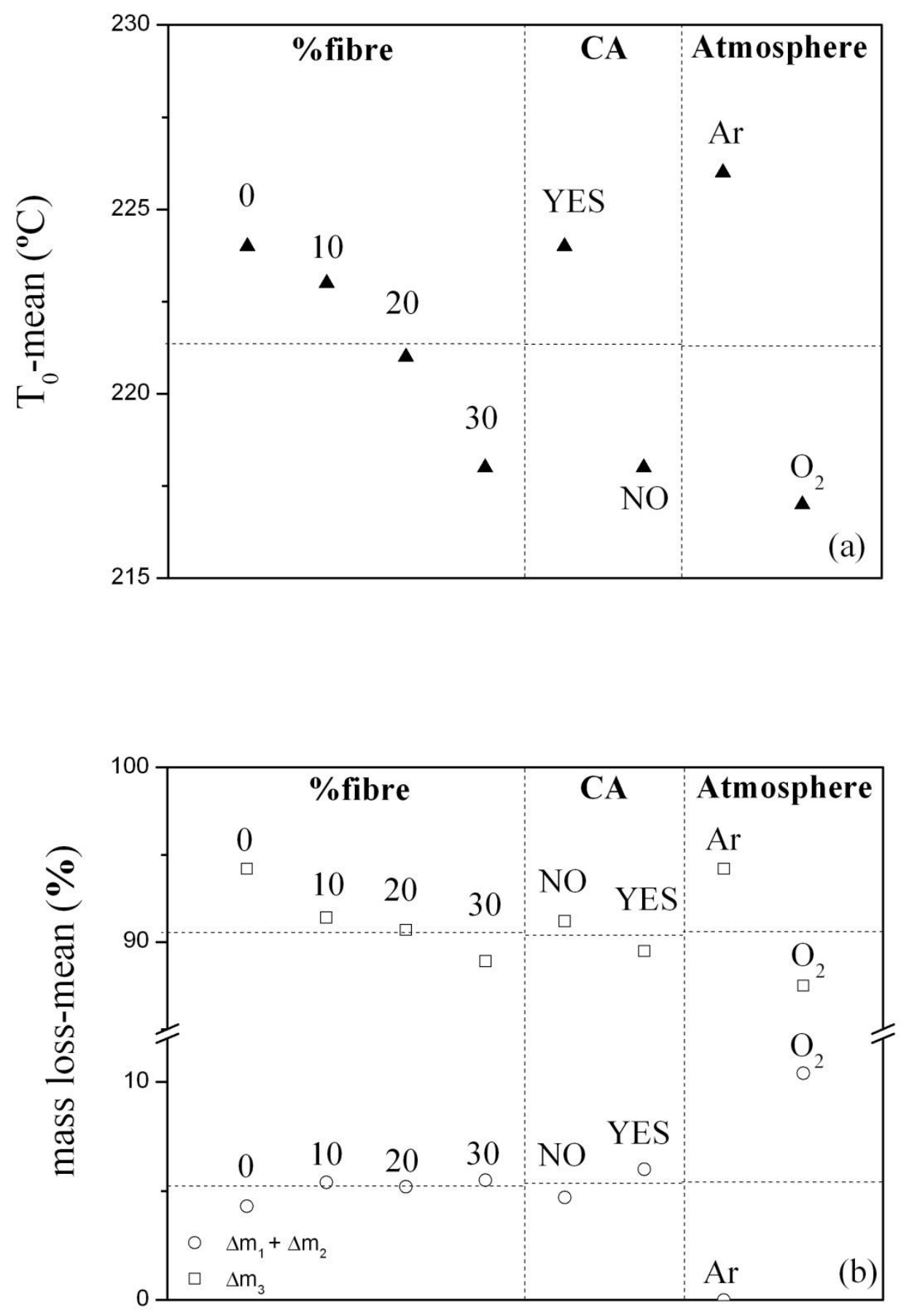

Fig 2. Main Effect Plots (MEP) of the statistical analysis for the variables temperature of decomposition - $\mathrm{T}_{0}$ (a) and mass loss $-\Delta \mathrm{m}_{\mathrm{i}}(\mathrm{b})$. 


\subsection{Assessment of the kinetic triplet to model the inert and oxidative decomposition kinetics}

The study of the kinetics of inert and oxidative decomposition is an essential step to define the operational conditions for correct performance of a thermo-chemical reactor. Equilibrium conditions can be assumed when performing preliminary studies for the feasibility of energy recovery processes. However, an accurate definition of the process for its further optimisation would require the implementation of the exact kinetic expression that define the precise reaction rates and conversions (Moliner et al. 2017b, 2017c).The extension of the kinetic law to a greater scale should take into account potential heat and mass transfer limitations. In this sense, spouted bed reactors present high isothermicity and excellent heat transfer between the phases and ensure the validity of the application of the kinetic results (Niksiar et al, 2015).

The three characteristic parameters defining a kinetic law are: apparent activation energy $(E a)$, preexponential factor $(A)$ and kinetic function $(f(\alpha))$, forming the so-called kinetic triplet, according to Eq. (2):

$$
\frac{d \alpha}{d t} \equiv \beta \cdot \frac{d \alpha}{d T}=A \cdot f(\alpha) \cdot k(T)=A \cdot f(\alpha) \cdot e^{\frac{-E_{a}}{R \cdot T}}
$$

The kinetic triplet of the main thermal decomposition processes of PLA/sisal biocomposites was assessed by the application of a methodology described elsewhere (Badia et al. 2012a, 2012b) to the previously deconvoluted curves. Shortly, the methodology combined the isoconversional evaluation of the apparent activation energy, the use of master curves to define the kinetic function, a minimisation procedure to evaluate the reaction order, and the application of the Coats-Redfern criterion to ensure the validity of the kinetic triplet. All the mentioned equations can be found in the Supplementary material. 


\subsubsection{Isoconversional analysis of apparent activation energies}

The isoconversional methods developed by Flynn-Wall-Ozawa (FWO) (Flynn and Wall, 1966, Ozawa, 1970), Kissinger-Akahira-Sunose (KAS) (Akahira-Sunose, 1971) and Vyazovkin (VYZ) (Vyazovkin, 1997) were applied to evaluate the dependence of the apparent activation energy $\left(\mathrm{Ea}_{\alpha}\right)$ with the conversion degree of the reaction $\alpha=\left(m_{0}-m_{i}\right) \cdot\left(m_{0}-m_{\infty}\right)^{-1}$ where $m$ is the mass with the subscripts 0 , i and $\infty$ stand for initial, instant and final times, respectively).

The range $\alpha=0.2-0.8$ was evaluated for all kinetic analysis, where the main reactions of the process occurred. An example of the goodness of the KAS method for the sample PLA30, tested under inert conditions is shown in Fig 3a, where the analysed data show high linearity. Similar results were obtained for the rest of PLA/sisal biocomposites, with linear regression coefficients higher than 0.98 .

The evolution of the apparent activation energy by the KAS method is shown in Fig $\mathbf{3 b}$, which varied between a $10 \%$ range throughout the whole decomposition process. This Ea range was narrow enough to consider the $\mathrm{Ea}$ as constant during the interval of study for further analyses (Badia et al. 2013).

The values of the apparent activation energy, as averaged from the calculations by the FWO, KAS and VYZ methods, for thermal decompositions taken under inert and oxidative conditions, are presented in Table 5. Despite the addition of fibres and the use of coupling agent did not result in a specific trend of Ea, the values varied between $\sim 150-175 \mathrm{~kJ} \cdot \mathrm{mol}^{-1}$ under inert conditions, and 150$195 \mathrm{~kJ} \cdot \mathrm{mol}^{-1}$ under oxidative conditions for the main thermal decomposition stage. Concerning the oxidative decomposition stage at higher conversion degrees, the Ea values were in the $\sim 180-215$ $\mathrm{kJ} \cdot \mathrm{mol}^{-1}$ range, because it corresponded to the decomposition of carbon species with high C-content (Amutio et al. 2012). 

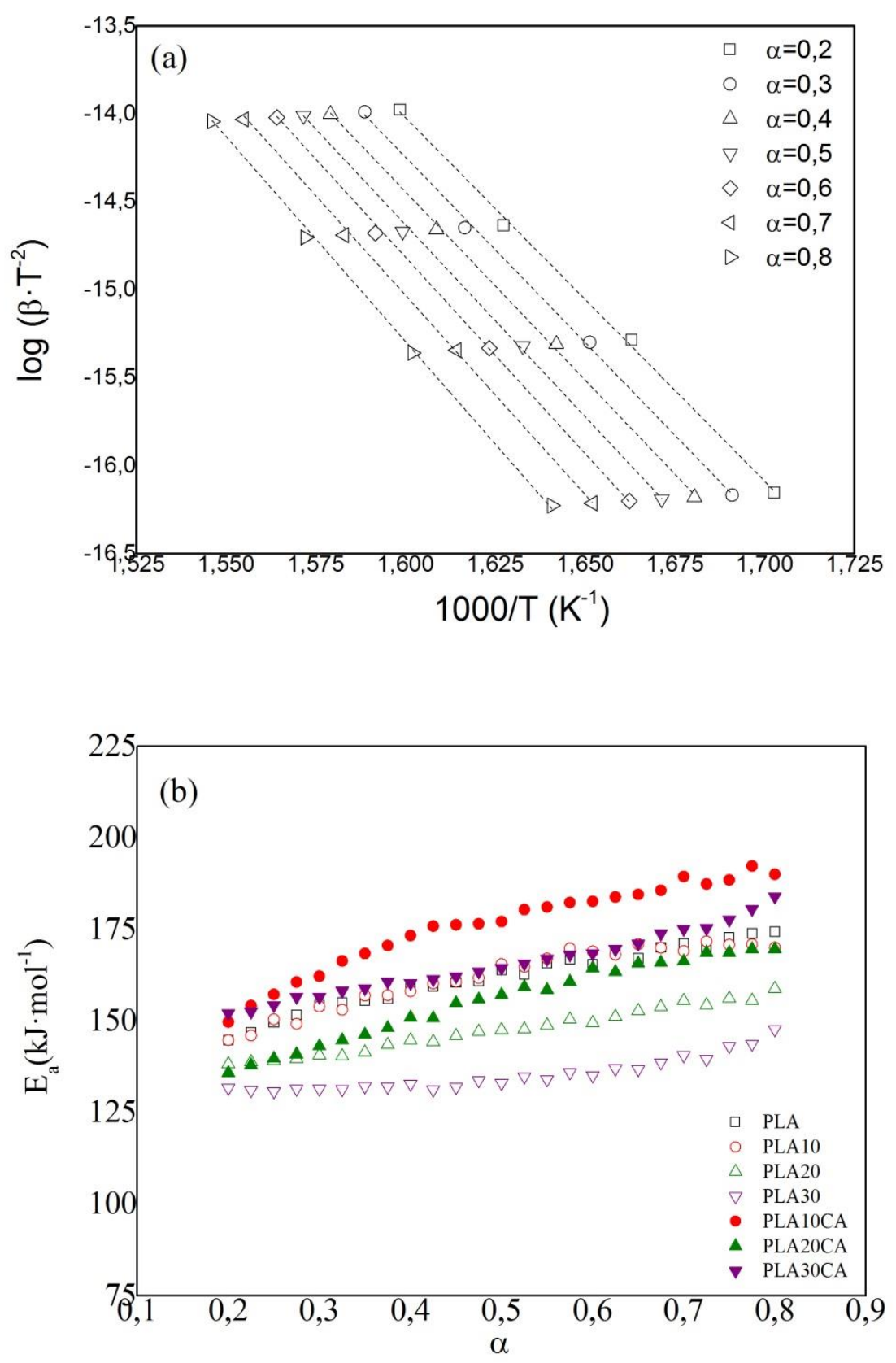

Fig 3. Goodness of the application of KAS method on PLA30 (a) and evolution of EaKAS for

PLA/sisal biocomposites under Ar (b). Note: maximum error values below $10 \%$. 
Table 5. Kinetic triplet of PLA biocomposites under inert and oxidative conditions and associated error values (e)

\begin{tabular}{|c|c|c|c|c|c|c|}
\hline \multirow[b]{2}{*}{ Conditions } & \multirow{3}{*}{$\begin{array}{l}\text { Material } \\
\text { PLA }\end{array}$} & \multicolumn{2}{|l|}{ Eaiso } & \multicolumn{2}{|l|}{$\ln (A)$} & \multirow{2}{*}{$\begin{array}{l}\text { Kinetic model: An } \\
\mathbf{n}\end{array}$} \\
\hline & & $(\mathrm{kJ} / \mathrm{mol})$ & e & $\mathbf{A}\left(\min ^{-1}\right)$ & e & \\
\hline \multirow{7}{*}{ Ar } & & 148 & $8,3 \%$ & 27,3 & $3,9 \%$ & 1,65 \\
\hline & PLA10 & 171 & $7,3 \%$ & 32,2 & $8,3 \%$ & 1,24 \\
\hline & PLA20 & 168 & $4,9 \%$ & 32,0 & $4,9 \%$ & 1,27 \\
\hline & PLA30 & 130 & $12,4 \%$ & 24,5 & $12,0 \%$ & 1,35 \\
\hline & PLA10CA & 174 & $4,9 \%$ & 32,7 & $5,5 \%$ & 1,08 \\
\hline & PLA20CA & 150 & $11,3 \%$ & 28,0 & $12,4 \%$ & 1,16 \\
\hline & PLA30CA & 169 & $4,2 \%$ & 31,8 & $5,4 \%$ & 1,08 \\
\hline \multirow{7}{*}{$\mathrm{O}_{2}-\mathrm{PEAK} 1$} & PLA & 173 & $1,4 \%$ & 33,5 & $0,9 \%$ & 1,50 \\
\hline & PLA10 & 175 & $2,0 \%$ & 34,4 & $2,2 \%$ & 1,14 \\
\hline & PLA20 & 131 & $9,4 \%$ & 24,8 & $5,5 \%$ & 1,40 \\
\hline & PLA30 & 147 & $4,9 \%$ & 28,6 & $5,2 \%$ & 2,11 \\
\hline & PLA10CA & 193 & $2,1 \%$ & 38,4 & $2,0 \%$ & 1,50 \\
\hline & PLA20CA & 173 & $5,6 \%$ & 34.2 & $5,2 \%$ & 1,60 \\
\hline & PLA30CA & 150 & $0,5 \%$ & 29,34 & $1,5 \%$ & 1,88 \\
\hline \multirow{7}{*}{$\mathrm{O}_{2}-$ PEAK 2} & PLA & - & - & - & - & - \\
\hline & PLA10 & 191 & $2,1 \%$ & 36,7 & $1,9 \%$ & 1,90 \\
\hline & PLA20 & 212 & $5,4 \%$ & 41,3 & $5,5 \%$ & 1,49 \\
\hline & PLA30 & 183 & $2,4 \%$ & 35,7 & $3,1 \%$ & 1,48 \\
\hline & PLA10CA & 200 & $1,9 \%$ & 39,1 & $2,0 \%$ & 1,60 \\
\hline & PLA20CA & 204 & $5,9 \%$ & 39,9 & $6,4 \%$ & 1,41 \\
\hline & PLA30CA & 199 & $0,8 \%$ & 39,0 & $1,3 \%$ & 1,38 \\
\hline
\end{tabular}

It is worth remarking that, in terms of recovery of energy, the Ea values of PLA/sisal biocomposites are lower than those of other commodity polymers like for example PP ( 100-250 $\mathrm{kJ} \cdot \mathrm{mol}^{-1}$ (Gunasee et al. 2016)) or PET $\left(\sim 150-175 \mathrm{~kJ} \cdot \mathrm{mol}^{-1}\right.$ (Badia et al. 2013)), and in the same order than other green polymers and green biocomposites, such as PHBV/sisal ( $~ 115-140 \mathrm{~kJ} \cdot \mathrm{mol}^{-1}$ (Moliner et al. 2017a)) or Mater-Bi KE/kenaf ( 160 kJ· mol-1 (Moriana et al. 2011)), therefore showing similar energy requirements to other plastics and bioplastics for energy valorisation processes. 


\subsubsection{Definition of the kinetic function by Master Curves}

In order to complete the design of the valoriser, the complete kinetic expression was evaluated and defined from the kinetic analysis of the biocomposites and the reduced Master Plot (MP) method. The experimental curves $(\mathrm{MP})$ are compared with the theoretical MP curves $\left(\mathrm{MP}_{\mathrm{t}}\right)$. The kinetic functions providing the best fitting defines the appropriate kinetic model (Gotor et al, 2000). The differential $\left(\mathrm{MP}_{\mathrm{f}}\right)$ and integral $\left(\mathrm{MP}_{\mathrm{g}}\right)$ curves were used and compared to experimental $\left(\mathrm{MP}_{\mathrm{e}}\right)$, choosing as the best model that which gave lower $\Omega$ (Badia et al. 2012a) in Eq. 3 .

$$
\Omega=\sum_{i}^{\beta}\left[\left(\sum_{0}^{0.5}\left(M P_{f e}-M P_{f t}\right)^{2}+\left(\sum_{0.5}^{1}\left(M P_{g e}-M P_{g t}\right)^{2}\right]\right.\right.
$$

The kinetic functions used for the analysis where the following: $R_{n}$ : contracting-order $(f(\alpha, n)=n \cdot(1-$ $\left.\alpha)^{(\mathrm{n}-1) / \mathrm{n}}\right) ; \mathrm{D}_{\mathrm{n}}$ : Diffusion $\left(\mathrm{f}(\alpha)=-(\ln (1-\alpha))^{-1}\right) ; \mathrm{A}_{\mathrm{n}}$ : Avrami-Erofeyev $\left(\mathrm{f}(\alpha, \mathrm{n})=\mathrm{n} \cdot(1-\alpha) \cdot[-\ln (1-\alpha)]^{1 / \mathrm{n}}\right)$; and $F_{n}: n$-order $\left(f(\alpha, n)=(1-\alpha)^{n}\right)$, being $n$ the reaction order in all cases. The complete description of all the kinetic functions can be found in the Supplementary Material.

The $\mathrm{MP}_{\mathrm{f}}$ and $\mathrm{MP}_{\mathrm{g}}$ curves are given in Fig. 4 for PLA (a,b), PLA30 (c,d) and PLA30CA (e,f) under Ar and at $5{ }^{\circ} \mathrm{C} \cdot \mathrm{min}^{-1}$ as model cases. Similar plots were obtained for the rest of PLA/sisal biocomposites regardless the heating rate and atmosphere of reaction. The results in Fig. 4 suggested that the decomposition of PLA/sisal biocomposites could be explained by an $A_{n}$ kinetic function. This is an advantage since it means that the same kinetic triplet determined for neat PLA (Badia et al. 2012a, 2012b) can model the kinetics of PLA/sisal biocomposites. To analytically calculate the exact order of reaction (n), the minimisation method described by Badia et al (Badia et al. 2012b) was applied to the main decomposition processes. 
C. Moliner, J.D. Badia, B. Bosio, E. Arato, R. Teruel-Juanes, T. Kittikorn, E. Strömberg, M. Ek, S. Karlsson, A. Ribes-Greus, Thermal kinetics for the energy valorisation of polylactide/sisal biocomposites, Thermochimica Acta, Volume 670, 2018,169-177
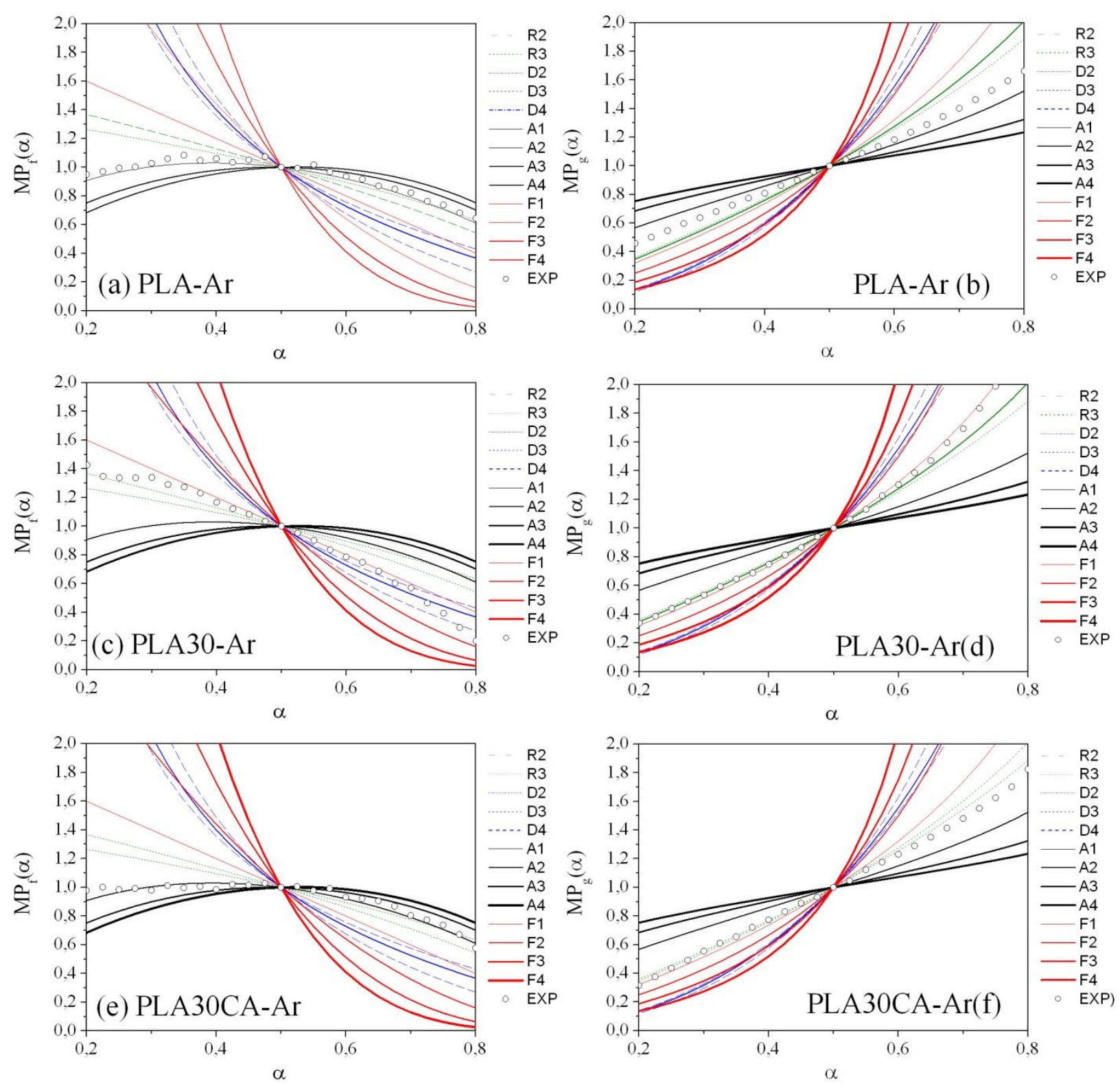

Fig 4. Master plots based on the differential (MPf $(\square)$ and integral (MPg ( $\square$ )) forms of the kinetic model compared to the experimental data (circles): PLA-Ar (a)-(b); PLA30-Ar (c)-(d); PLA30CA$\operatorname{Ar}(\mathrm{e})-(\mathrm{f})$; (solid black lines: An, solid red lines: Fn, dashed blue lines: Dn, dashed green lines: Rn, circles: experimental data) 


\subsubsection{Completion of the kinetic triplet: $n$ and pre-exponential factor}

The exact order of reaction was obtained as a result of the accomplishment of the Coats-Redfern criterion according to which the coordinates $[\mathrm{x}, \mathrm{y}]$ in $\mathrm{Eq}(4)$ should lie on the same straight line for all heating rates.

$$
\left[\ln \frac{\beta \cdot g(\alpha)}{T^{2}}\right]_{y}=\ln \frac{A_{\beta} \cdot R}{E a_{\beta}}+\frac{E a_{\beta}}{R} \cdot\left[\frac{1}{T}\right]_{x}
$$

with $\mathrm{g}(\alpha)$ being the integral form of the kinetic model previously obtained and $\mathrm{R}$ the ideal gas constant $\left(8.31 \mathrm{~J} \cdot \mathrm{mol}^{-1} \cdot \mathrm{K}^{-1}\right)$.

Finally, the pre-exponential factor (ln A) was obtained as the intercept in the origin of Eq. (4). Accordingly, the kinetic triplet corresponding to the main decomposition process for PLA and PLA/sisal biocomposites is completed in Table 4. The validation of the kinetic parameters is shown in Fig. 5 for PLA30CA under $\mathrm{O}_{2}$, as a model case, where all data lay in the same straight line. The rest of PLA/sisal biocomposites showed similar validation of parameters and are not shown for the sake of conciseness.

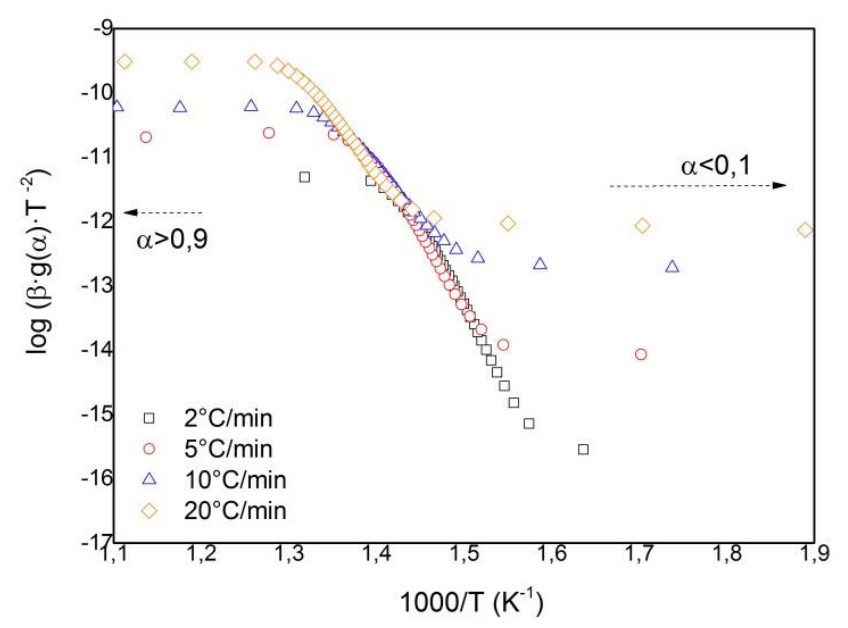

Fig 5. Validation of the goodness of the kinetic triplet for PLA30CA-O2 
To sum up, it seemed reasonable to state that the energy valorisation of PLA/sisal biocomposites was affordable both under inert and oxidative conditions, without relevant modifications of the operational settings in comparison to those of PLA.

\section{Conclusions}

The thermal stability and decomposition kinetics of PLA/sisal biocomposites was discussed to evaluate their suitability for their use in energy recovery processes such as pyrolysis and combustion.

The suitability and optimal operational parameters of the inert and oxidative decompositions of PLA/sisal biocomposites was evaluated. The influence of the addition of sisal up to $30 \%$ wt, the presence of coupling agent, and the atmosphere of operation, i.e. inert or oxidative was discussed. The trigger of decomposition was more sensitive to oxidative conditions and for biocomposites with higher load of sisal and presence of coupling agent. The minimum temperature of reaction and activation energy to ensure the decomposition of all the biocomposites were obtained for pyrolysis and complete oxidation processes.

From an overall point of view, a minimum temperature of $240{ }^{\circ} \mathrm{C}$ and activation energy of 174 $\mathrm{kJ} \cdot \mathrm{mol}^{-1}$ would be necessary to carry out the reaction of pyrolysis of the PLA and its biocomposites with sisal. For the case of oxidative reactions, $225^{\circ} \mathrm{C}$ and $190 \mathrm{~kJ} \cdot \mathrm{mol}^{-1}$ would be required in order to perform the complete oxidation of the biocomposites. The same kinetic law following the Avrami-Erofeyev $A_{n}$, with reaction order $n$ between 1 and 2, was found feasible for modelliing the decomposition kinetics of the PLA/sisal biocomposites both at inert and oxidative conditions, facilitating the energy valorisation regardless their composition. All biocomposites showed a mean high heating value of $15 \mathrm{MJ} / \mathrm{kg}$ indicating their suitability for energy recovery processes 
C. Moliner, J.D. Badia, B. Bosio, E. Arato, R. Teruel-Juanes, T. Kittikorn, E. Strömberg, M. Ek, S. Karlsson, A. Ribes-Greus, Thermal kinetics for the energy valorisation of polylactide/sisal biocomposites, Thermochimica Acta, Volume 670, 2018,169-177

In summary, a joint energy valorisation could be carried out as the parameters obtained from both processes did not vary in great measure with the addition of fibres or coupling agent to the polymeric matrix.

\section{Acknowledgements}

The Spanish Ministry of Economy and Competitiveness and European Regional Development Funds are acknowledged for the projects POLYCELL (ENE2014-53734-C2-1-R) and TETRA-SEC (UPOV13-3E-1947). Generalitat Valenciana is thanked for the APOSTD/2014/041 for J.D. Badia. The financial support given by the Prince of Songkla University and KTH Royal Institute of Technology is gratefully acknowledged. Rossella Acerbo and Emanuele Righi are gratefully acknowledged for their activity in the framework of their Bachelor Thesis.

\section{References}

Akahira T. and Sunose T., Transactions joint convention of four electrical institutes, 1971.

Al-Salem S. M., Lettieri P., and Baeyens J., Recycling and recovery routes of plastic solid waste (PSW): A review, Waste Manag., vol. 29, no. 10, pp. 2625-2643, 2009.

Amutio M., Lopez G., Aguado R., Artetxe M., Bilbao J., Olazar M.. Kinetic study of lignocellulosic biomass oxidative pyrolysis, Fuel 95 305-311. 2012.

ASTM D7582-12. Standard Test Methods for Proximate Analysis of Coal and Coke by Macro Thermogravimetric Analysis, ASTM International, West Conshohocken, PA, 2012

Badía J. D., Santonja-Blasco L., Moriana R., and Ribes-Greus A., Thermal analysis applied to the characterization of degradation in soil of polylactide: II. on the thermal stability and thermal decomposition kinetics, Polym. Degrad. Stab., vol. 95, no. 11, pp. 2192-2199, 2010. 
Badía J. D., Strömberg E., Ribes-Greus A., and Karlsson S. A statistical design of experiments for optimizing the MALDI-TOF-MS sample preparation of polymers. An application in the assessment of the thermo-mechanical degradation mechanisms of poly (ethylene terephthalate), Anal. Chim. Acta 692 (1-2) 85-95, 2011.

Badia J. D., Santonja-Blasco L., Martínez-Felipe A., and Ribes-Greus A., A methodology to assess the energetic valorization of bio-based polymers from the packaging industry: Pyrolysis of reprocessed polylactide, Bioresour. Technol., vol. 111, pp. 468-475, 2012a.

Badia J. D., Santonja-Blasco L., Martínez-Felipe A., and Ribes-Greus A., Reprocessed polylactide: studies of thermo-oxidative decomposition., Bioresour. Technol., vol. 114, pp. 622-8, 2012b.

Badia J. D., Martinez-Felipe A., Santonja-Blasco L., and Ribes-Greus A., Thermal and thermooxidative stability of reprocessed poly(ethylene terephthalate), J. Anal. Appl. Pyrolysis, vol. 99, pp. 191-202, 2013.

Badia J. D., Gil-Castell O., and Ribes-Greus A., Long-term properties and end-of-life of polymers from renewable resources, Polym. Degrad. Stab., 2017a.

Badia J.D., JStrömberg E., Kittikorn T., Ek M., Karlsson S., Ribes-Greus A. Relevant factors for the eco-design of polylactide/sisal biocomposites to control biodegradation in soil in an endof-life scenario. Polymer degradation and stability, 143, 9-19. $2017 \mathrm{~b}$.

Badia J.D. Reig-Rodrigo P. Teruel-Juanes R. Kittikorn T., Strömberg E., Ek M., Karlsson S., RibesGreus A. Effect of sisal and hydrothermal ageing on the dielectric behaviour of polylactide/sisal biocomposites. Composites Science and Technology Volume 149, Pages 110. $2017 \mathrm{c}$. 
Box, G. E. P. HUNTER, j. S.; HUNTER, WG Statistics for experiments: designs, innovation and discovery. New Jersey: John Wiley \& Sons, Inc. 2005

Cai, J., Xu, D., Dong, Z., Yu, X., Yang, Y., Banks, S., \& Bridgwater, A. V. Processing thermogravimetric analysis data for isoconversional kinetic analysis of lignocellulosic biomass pyrolysis: Case study of corn stalk. Renewable and sustainable energy reviews. In press. 2017. DOI: 10.1016/j.rser.2017.09.113.

Chandrasekaran A, Ramachandran S, Subbiah S, Determination of kinetic parameters in the pyrolysis operation and thermal behavior of Prosopis juliflora using thermogravimetric analysis. Bioresour Technol. 233:413-422. 2017. doi: 10.1016/j.biortech.2017.02.119.

Coles, S. R., \& Meredith, J. Biopolymers and biocomposites. Encyclopedia of automotive engineering, 1-11. 2014.

de Moura, I. G., de Sá, A. V., Abreu, A. S. L. M., \& Machado, A. V. A. Bioplastics from agrowastes for food packaging applications. In Food Packaging 223-263, 2017.

Dorez G. Taguet A., Ferry L., Lopez-Cuesta J.M. Thermal and fire behavior of natural fibers/PBS biocomposites. Polymer Degradation and Stability, Volume 98, Issue 1, Pages 87-95.2013. DOI: 10.1016/j.polymdegradstab.2012.10.026.

Fang M. X., Shen D. K., Li Y. X., Yu C. J., Luo Z. Y., and Cen K. F. Kinetic study on pyrolysis and combustion of wood under different oxygen concentrations by using TG-FTIR analysis, J. Anal. Appl. Pyrolysis, vol. 77, no. 1, pp. 22-27, 2006.

Flynn J. H. and Wall L. A., A quick, direct method for the determination of activation energy from thermogravimetric data, J. Polym. Sci. Part C Polym. Lett., vol. 4, no. 5, pp. 323-328, 1966. 
Gil-Castell O., Badia J., Kittikorn T., Strömberg E., Martínez-Felipe A., Ek M., Karlsson S., and Ribes-Greus A., Hydrothermal ageing of polylactide/sisal biocomposites. Studies of water absorption behaviour and physicochemical performance, Polym. Degrad. Stab., vol. 132, pp. 87-96, 2016a.

Gil-Castell O., Badia J. D., Kittikorn T., Strömberg E., Ek M., Karlsson S., and Ribes-Greus A., Impact of hydrothermal ageing on the thermal stability, morphology and viscoelastic performance of PLA/sisal biocomposites, Polym. Degrad. Stab., 2016 b.

Gil-Castell O, Badia JD, Ribes-Greus A. Suitability of Blends from Virgin and Reprocessed Polylactide: Performance and Energy Valorization Kinetics Journal of Renewable Materials 6 (4) 370-382, 2018.

Gotor F.J., Criado J.M., Malek J., Koga N. Kinetic analysis of solid-state reactions: the universatility of master plots for analysing isothermal and non-isothermal experiments. Journal of Physical Chemistry A 104 10777-10782. 2000

Gunasee S.D., Carrier M., Gorgens J. F., Mohee R. Pyrolysis and combustion of municipal solid wastes: Evaluation of synergistic effects using TGA-MS. Journal of Analytical and Applied Pyrolysis Volume 121, Pages 50-61. 2016

ISO 291. Plastics. Standard atmospheres for conditioning and testing. 1997.

John M.J., Thomas S. Biofibres and biocomposites. Carbohydrate Polymers 71, 343-363, 2008

Josep P.V., Joseph K., Thomas S., Pillai C.K.S., Prasad V.S., Groeningckx G., Sarkissova M. The thermal and crystallization studies of short sisal fibre reinforced polypropylene composites. Composites: part A 34, 253-266. 2003 
Kittikorn T., Tuning the long-term properties to control biodegradation by surface modifications of agricultural fibres in biocomposites. KTH Royal Institute of Technology, 2013.

Kissinger H. E., Reaction kinetics in differential thermal analysis, Anal. Chem., vol. 29, no. 11, pp. 1702-1706, 1957.

Kopinke F.D., Remmler M., Mackenzie K., Moder M., Wachsen O. Thermal decomposition of biodegradable polyesters. II. Poly(lactic acid) Polym. Degrad. Stab., 53 , pp. 329-342, 1996

Mehmood MA, Ye G, Luo H, Liu C, Malik S, Afzal I, Xu J, Ahmad MS. Pyrolysis and kinetic analyses of Camel grass (Cymbopogon schoenanthus) for bioenergy. Bioresour Technol. 228:18-24. 2017. doi: 10.1016/j.biortech.2016.12.096.

Moliner C., Bosio B., Arato E., and Ribes A., Thermal and thermo-oxidative characterisation of rice straw for its use in energy valorisation processes, Fuel, vol. 180, pp. 71-79, 2016 a.

Moliner C., Aguilar K., Bosio B., Arato E., Ribes A.. Thermo-oxidative characterisation of the residues from persimmon harvest for its use in energy recovery processes. Fuel Processing Technology 152, 421-429, $2016 b$.

Moliner C., Badia J.D., Bosio B., Arato E., Kittikorn T., Stromberg E., Teruel-Juanes R., Ek M., Karlsson S., Ribes-Greus A. Thermal and thermo-oxidative stability and kinetics of decomposition of PHBV/sisal composites. Chemical Engineering Communications, 205:2, 226-237 . 2017a.

Moliner C., Marchelli F., Bosio B., Arato E. Modelling of spouted and spout-fluid beds: key for their successful scale-up. Energies 10(11), 1729. 2017b. doi:10.3390/en10111729 
C. Moliner, J.D. Badia, B. Bosio, E. Arato, R. Teruel-Juanes, T. Kittikorn, E. Strömberg, M. Ek, S. Karlsson, A. Ribes-Greus, Thermal kinetics for the energy valorisation of polylactide/sisal biocomposites, Thermochimica Acta, Volume 670, 2018,169-177

Moliner, C. Badia, J.D., Bosio, B., Arato E, Capurro, M., Ribes-Greus, A. Mechanical and thermal performance of PLA and PHBV-based biopolymers as potential alternatives to PET. Chemical Engineering Transactions 57, pp. 1417-1422, 2017c.Monteiro S., Calado V., Rodriguez R., Margem F.. Thermogravimetric behavior of natural fibers reinforced polymer composites-an overview. Materials Science \& Engineering A 557 17-28. 2012.

Moriana R., Vilaplana F., Karlsson S., Ribes-Greus A., Improved thermo-mechanical properties by the addition of natural fibres in starch-based sustainable biocomposites. Composites A, 42, 30-40. 2011.

Moustafa H., Guizani C. Dufresne A. Sustainable biodegradable coffee grounds filler and its effect on the hydrophobicity, mechanical and thermal properties of biodegradable PBAT composites. Journal of Applied Polymer Science. Volume 134, Issue 8, 2017. DOI: 10.1002/app.44498.

Moussou H., Ahlafi H., Aazza M., Bourakhouadar M. Kinetics and mechanism of the thermal degradation of biopolymers chitin and chitosan using thermogravimetric analysis. Polymer Degradation and Stability, 130, 1-9. 2016. DOI: 10.1016/j.polymdegradstab.2016.05.016.

Niaounakis, M. Biopolymers: Applications and trends. William Andrew, 2015.

Niksiar A., Faramarzi A.H., Sohrabi M. Kinetic study of polyethylene therephtalate (PET) pyrolysis in a spouted bed reactor. Journal of Analytical and Applied Pyrolysis 113, pp. 419-425, 2015.

Oksman K., Skrifvars M., and Selin J.-F., Natural fibres as reinforcement in polylactic acid (PLA) composites, Compos. Sci. Technol., vol. 63, no. 9, pp. 1317-1324, 2003.

Ozawa T., Kinetic analysis of derivative curves in thermal analysis, J. Therm. Anal., vol. 2, no. 3, pp. 301-324, 1970. 
C. Moliner, J.D. Badia, B. Bosio, E. Arato, R. Teruel-Juanes, T. Kittikorn, E. Strömberg, M. Ek, S. Karlsson, A. Ribes-Greus, Thermal kinetics for the energy valorisation of polylactide/sisal biocomposites, Thermochimica Acta, Volume 670, 2018,169-177

Pacheco-Torgal, F. Introduction to biopolymers and biotech admixtures for eco-efficient construction materials. In Biopolymers and Biotech Admixtures for Eco-Efficient Construction Materials, pp. 1-10, 2016.

Parikh J., Channiwalab S.A., Ghosal G.K. A correlation for calculating HHV from proximate analysis of solid fuels. Fuel 84, pp. 487-494, 2005.

Prime RB, Bair HE, Vyazovkin S, Gallagher PK, Riga A. Thermogravimetric analysis (TGA). In: Menczel JD, Prime RB (eds) Thermal analysis of polymers: fundamentals and applications. John Wiley \& Sons Inc., New York, pp 241-317. 2008. doi: 10.1002/9780470423837.ch3

Seethalakshmi A.N., Subramanian S., Muthuchelian, K. Thermal, structural, mechanical and electrical properties of biomaterial prosopis juliflora. International Journal of Current Research Vol. 5, Issue, 10, pp.3116-3120, 2013.

Vyazovkin S.. Advanced isoconversional method. Journal of thermal analysis 49 1493-1499. 1977 
C. Moliner, J.D. Badia, B. Bosio, E. Arato, R. Teruel-Juanes, T. Kittikorn, E. Strömberg, M. Ek, S. Karlsson, A. Ribes-Greus, Thermal kinetics for the energy valorisation of polylactide/sisal biocomposites, Thermochimica Acta, Volume 670, 2018,169-177

THERMAL KINETICS FOR THE ENERGY VALORISATION OF POLYLACTIDE/SISAL BIOCOMPOSITES

C.Moliner ${ }^{1,2}$, J.D. Badia ${ }^{2,3}$, B. Bosio ${ }^{1}$, E. Arato ${ }^{1}$, R. Teruel-Juanes ${ }^{2}$, T. Kittikorn ${ }^{4,5}$, E. Strömberg ${ }^{4}$, $\mathrm{M.Ek}^{4}$, S.Karlsson ${ }^{4}$, A.Ribes-Greus, ${ }^{2, *}$ 
1. Determination of the activation energy with isoconversional methods

Isoconversional methods use data from multi-linear non-isothermal experiments without taking modelistic assumptions for the kinetic analysis which are the main source of error in model-fitting methods.

Among the integral linear methods, the most widely used are the expressions developed by FlynnWall-Ozawa (FWO) supported on Doyle's integral approximation and Kissinger-Akahira-Sunose (KAS) which are represented by Eq. (S1) and Eq. (S2), respectively. These methods are based on linear functions which slopes defined the Ea at a fixed $\alpha$.

$$
\begin{gathered}
{[\log (\beta)]_{y}=\log \left(\frac{A_{\alpha} \cdot E a_{\alpha}}{R \cdot g(\alpha)}\right)-2.315-\frac{0.457 \cdot E a_{\alpha}}{R} \cdot\left[\frac{1}{T_{\alpha}}\right]_{x}} \\
{\left[\ln \left(\frac{\beta}{T^{2}}\right)\right]_{y}=\ln \left(\frac{A_{\alpha} \cdot R}{E a_{\alpha} \cdot g(\alpha)}\right)-\frac{E a_{\alpha}}{R} \cdot\left[\frac{1}{T_{\alpha}}\right]_{x}}
\end{gathered}
$$

With $g(\alpha)$ being the inverse integral kinetic model defined as:

$$
g(\alpha)=\int_{0}^{\alpha}(f(\alpha))^{-1} \cdot d \alpha
$$

Vyazovkin and Dollimore (VYZ) definition in a more accurate integral non-linear method based on the expression:

$$
\Omega=\left|\sum_{i=1}^{h} \sum_{j \neq 1}^{h} \frac{\beta_{j} \cdot I\left(E a_{\alpha} T_{\alpha}^{i}\right)}{\beta_{i} \cdot I\left(E a_{\alpha} T_{\alpha}^{j}\right)}\right|, I\left(E a_{\alpha} T_{\alpha}^{i, j}\right)=p_{i, j}\left(\frac{E a_{\alpha}}{R \cdot T_{\alpha}}\right)
$$

With $\mathrm{i}$ and $\mathrm{j}$ counters through the $\mathrm{h}$ experiments performed at the different heating rates. The activation energy $\mathrm{Ea}_{\alpha}$ is the value that minimises $\Omega$ in Eq. S4 for a given $\alpha$. 


\section{Master Plots}

The reaction model may adopt various expressions, based on nucleation and nuclei growth, phase boundary reactions, diffusion or chemical reactions. Master Plots (MP) are reference theoretical curves $\left(\mathrm{MP}_{\mathrm{t}}\right)$ depending on the kinetic model, but generally independent of the kinetic parameters of the process. The experimental kinetic data can be easily transformed into experimental curves $\mathrm{MP}_{\mathrm{e}}$ that can be compared with the $\mathrm{MP}_{\mathrm{t}}$ to allow the selection of the appropriate kinetic model of the process under investigation.

There exist three main types of $\mathrm{MP}_{\mathrm{t}}$, those based on the differential form $\left(\mathrm{MP}_{\mathrm{f}}\right)$ of the generalized kinetic equation (Eq S5); those based on the integral form ( $\mathrm{MP}_{\mathrm{g}}$ ) (Eq. S6); and the most common one that combines both differential and integral forms $\left(\mathrm{MP}_{\mathrm{fg}}\right)$, that are usually reduced at $\alpha=0.5$ for better visualization.

Assuming A and Ea constant, due to interdependence of kinetic parameters, and using a reference point at $\alpha=0.5$, the theoretical $\mathrm{MP}_{\mathrm{t}}$ and the expression for the reduced form of the experimental data can be drawn:

$$
\begin{gathered}
\frac{\frac{d \alpha}{d \theta}}{\left.\frac{d \alpha}{d \theta}\right|_{0.5}}=\frac{f(\alpha)}{f(0.5)}=M P_{t}=M P_{e}=\frac{\frac{d \alpha}{d t} \cdot e^{\frac{E a}{R \cdot T}}}{\left.\frac{d \alpha}{d t}\right|_{0.5} \cdot e^{\frac{E a}{R \cdot T \mid 0.5}}} \\
\frac{\theta}{\theta_{0.5}}=\frac{g(\alpha)}{g(0.5)}=M P_{t}=M P_{e}=\frac{p(x)}{p\left(x_{0.5}\right)}
\end{gathered}
$$

3. Independence of the heating rate

In order to complete the kinetic triplet, the pre-exponential factor A has to be found. As well, the Perez-Maqueda et al criterion has to be accomplished; that is, the independence of the activation parameters $E a$, A on the heating rate $\beta$. This criterion is usually employed with Ea and A invariable with the aid of the Coats-Redfern equation written in the form:

$$
\left[\ln \frac{\beta \cdot g(\alpha)}{T^{2}}\right]_{y}=\ln \frac{A \cdot R}{E a}+\frac{E a}{R} \cdot\left[\frac{1}{T}\right]_{x}
$$

Where $\{x, y\}$ should lie on the same straight line to all heating rates. 
C. Moliner, J.D. Badia, B. Bosio, E. Arato, R. Teruel-Juanes, T. Kittikorn, E. Strömberg, M. Ek, S. Karlsson, A. Ribes-Greus, Thermal kinetics for the energy valorisation of polylactide/sisal biocomposites, Thermochimica Acta, Volume 670, 2018,169-177

\section{Annex. Open access policies}

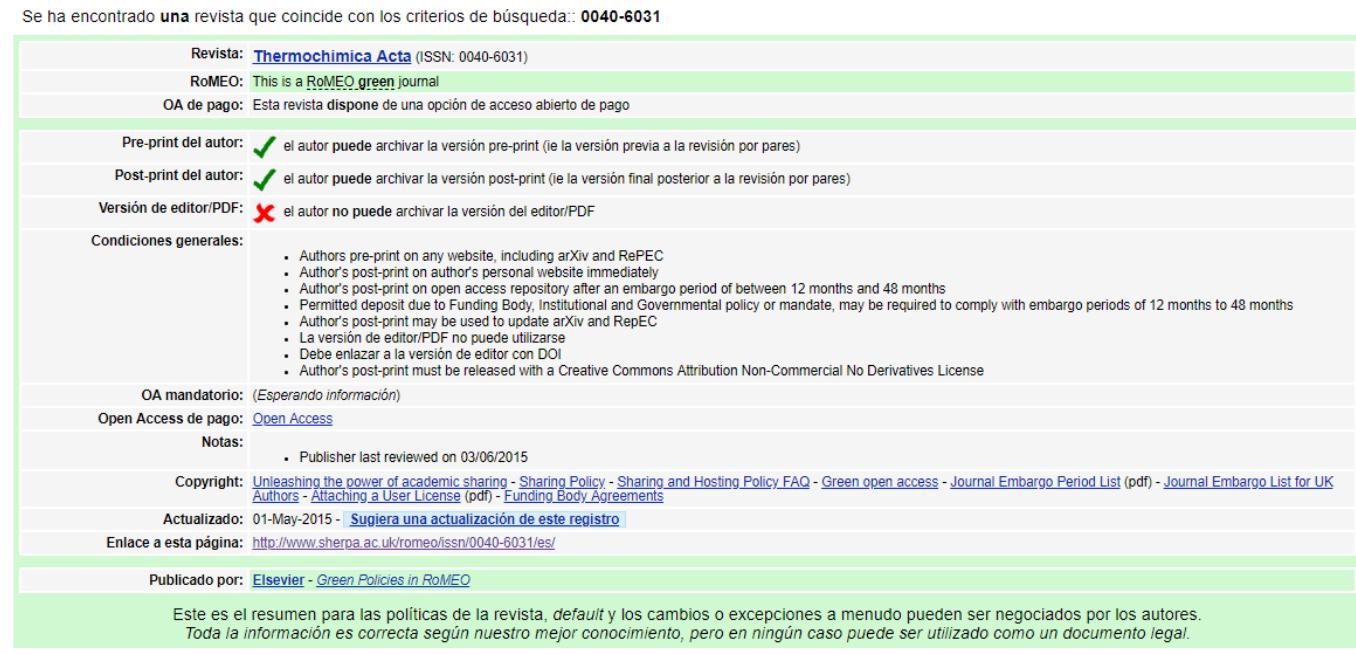

